\title{
NÍVEIS DE SOMBREAMENTO INFLUENCIAM A PRODUÇÃO DE MUDAS DE Mentha x villosa huds. (HORTELÃ)
}

\author{
SHADING LEVELS INFLUENCE THE PRODUCTION OF Mentha $x$ villosa Huds. (MINT) \\ SEEDLINGS \&
}

\section{LOS NIVELES DE SOMBRA INFLUYEN EN LA PRODUCCIÓN DE PLÁNTULAS DE Mentha $x$ villosa Huds. (MENTA) \&}

Recebido em: 16/11/2020 - Aprovado em: 13/01/2021 - Publicado em: 20/04/2021

http://dx.doi.org/10.18011/bioeng2021v15n1p127-141

Elias Vinícius Wanderline Quaresma1 (eliasvinicius-77@hotmail.com)

Rodrigo Pereira de Assis Otto' (rodrigopaotto@hotmail.com)

Cleberton Correia Santos ${ }^{1}$ (cleber_frs@yahoo.com.br)

Juliana Milene Silverio' (juliana.milene@hotmail.com)

Guilherme Henrique de Souza Loli' (loli.agroufgd@gmail.com)

Maria do Carmo Vieira1 (mariavieira@ufgd.edu.br)

${ }^{1}$ Universidade Federal da Grande Dourados (UFGD), Dourados/MS, Brasil.

\section{RESUMO}

A hortelã (Mentha x villosa Huds., Lamiaceae) é planta medicinal e aromática, geralmente utilizada no preparo de chás e sucos. Por meio deste estudo foi suposto que o nível de interceptação luminosa do ambiente de produção de mudas pode influenciar a propagação vegetativa da hortelã. Realizou-se o experimento, avaliando quatro disponibilidades luminosas baseando-se nos níveis de sombreamento de $0 \%$ (pleno sol), $30 \%, 50 \%$ e $70 \%$. As estacas foram coletadas no período matutino, acondicionadas em recipiente com água, e padronizadas com $7,0 \mathrm{~cm}$ de comprimento e quatro folhas. Posteriormente, realizou-se o enterrio de $1 / 3$ da estaca em substrato constituído de Latossolo Vermelho Distroférrico + Tropstrato $^{\circledR}(3: 1, \mathrm{v} / \mathrm{v})$. As avaliações das características não destrutivas e destrutivas foram realizadas aos 75 dias após o enterrio das estacas. Em geral, as mudas de hortelã apresentaram valores de sobrevivência $>80 \%$. O maior valor de altura, comprimento de raiz e relação altura/diâmetro ocorreu nas mudas produzidas sob $70 \%$ de sombra. Por outro lado, mudas produzidas à pleno sol $(0 \%)$ apresentam maior número de brotos, área foliar e produção de massa fresca de folhas, caules e raízes. Recomenda-se para a produção de mudas de hortelã que sua propagação vegetativa por estaquia seja feita em ambiente à pleno sol.

Palavras-chave: Estaquia. Estiolamento. Luminosidade. Planta medicinal. Propagação vegetativa.

Artigo publicado sob a licença Creative Commons - Atribuição 4.0 Internacional (CC BY 4.0). 


\section{INTRODUÇÃO}

A hortelã (Mentha x villosa Huds., Lamiaceae) é uma planta de interesse medicinal e aromático. Na medicina popular, suas folhas são utilizadas no preparo de chás como antigripal, calmante, antiespasmódico, antidiarreico e para cefaleia (MESSIAS et al., 2015), tornando-a uma das espécies listadas na Relação Nacional de Plantas Medicinais de Interesse ao SUS (Sistema Único de Saúde) (BRASIL, 2009). Suas folhas são utilizadas no preparo de sucos e pratos na culinária por promover um aroma agradável.

O óleo essencial das folhas de hortelã apresenta potencial larvicida do mosquito da dengue (Aedes aegypti L.) (LIMA et al., 2006) e contribui nas funções cardíacas (MATOSROCHA et al., 2020). O uso das folhas também apresenta propriedades antiparasitárias (FONSECA et al., 2020), e o extrato hidroalcólico foi eficaz para o controle da fase juvenil de nematoides gastrintestinais de bovinos por meio de teste in vitro (NASCIMENTO et al., 2009).

Considerando a importância e notável valor da hortelã por seus diversos usos e benefícios, seu cultivo tem aumentado cada vez mais em hortas comerciais, hortas verticais domiciliares ou em jardins agromedicinais, sendo que sua propagação é vegetativa, realizada por meio da estaquia, tanto do ramo principal quanto dos laterais.

O uso da estaquia na propagação, além de ser uma técnica de fácil execução e de baixo custo, permite a obtenção de mudas padronizadas, uma vez que apresentam características semelhantes às da planta mãe (matriz) (MARTINS et al., 2015), tornandose uma muda clone.

$\mathrm{Na}$ literatura estudos de produção de mudas especificamente da $M . \mathrm{x}$ villosa são incipientes, tendo sido encontrados trabalhos sobre sua propagação em função de substratos orgânicos (PAULUS; PAULUS, 2007) e do tipo de estacas e presença de folhas (COSTA et al., 2016).

O sombreamento influencia diretamente a produção de mudas de diversas espécies, pois está relacionado ao conteúdo de nitrogênio foliar, pigmentos fotossintéticos, produção e particionamento de fotoassimilados entre os diferentes órgãos em formação (REIS et al., 2016; COSTA et al., 2018). No entanto, informações sobre mudas da hortelã em formação em resposta aos níveis de sombreamento são insuficientes, fazendo-se necessários estudos nessa área do conhecimento. 
A capacidade de sobrevivência e de crescimento das mudas é variável com a tolerância/plasticidade fisiológica de cada espécie e as condições de cultivo. Portanto, objetivou-se com este estudo avaliar o efeito de níveis de sombreamento na produção de mudas de hortelã (Mentha x villosa Huds).

\section{MATERIAL E MÉTODOS}

O experimento foi desenvolvido em setembro a novembro de 2018 na Faculdade de Ciências Agrárias (22011'43.7"S e 5456'08.5"W, 452 m), da Universidade Federal da Grande Dourados (UFGD), Dourados - MS, Brasil. Para propagação da hortelã, coletaramse estacas de plantas matrizes de 6 meses localizadas no Horto de Plantas Medicinais, da UFGD, no período matutino utilizando tesoura de poda, as quais foram acondicionadas em recipiente com água (Figura $1 \mathrm{~A}$ ), visando evitar a desidratação e oxidação do nó basal. Posteriormente, as estacas foram padronizadas com comprimento de $7,0 \mathrm{~cm}$ e quatro folhas, e mantidas em recipiente com água até momento de enterrio.

Preparou-se o substrato base por meio da homogeneização de Latossolo Vermelho Distroférrico + Tropstrato $^{\circledR}(3: 1, \mathrm{v} / \mathrm{v})$, que apresentou os seguintes atributos químicos de acordo com a metodologia de Silva (2009): $\mathrm{pH} \mathrm{CaCl}_{2}=5,94 ; \mathrm{P}=42,65 \mathrm{mg} \mathrm{dm}^{3} ; \mathrm{K}=1,99$ $\mathrm{cmol}_{\mathrm{c}} \mathrm{dm}^{3} ; \mathrm{Ca}=13,28 \mathrm{cmol}_{\mathrm{c}} \mathrm{dm}^{3} ; \mathrm{Mg}=19,00 \mathrm{cmol}_{\mathrm{c}} \mathrm{dm}^{3} ; \mathrm{H}+\mathrm{Al}=2,37 \mathrm{cmol}_{\mathrm{c}} \mathrm{dm}^{3} ; \mathrm{V}(\%)=$ 62,88 , e os atributos físicos: porosidade total $=61 \%$ e densidade real $=0,94 \mathrm{~g} \mathrm{~cm}^{3}$.

Logo após, preencheram-se os recipientes plásticos com capacidade de $500 \mathrm{~mL}$ com o substrato base, o qual foi umedecido e feito o enterrio de $1 / 3$ das estacas (Figura 1B). As mudas foram dispostas sob quatro níveis de sombreamento: 0\% (exposição direta ao pleno sol), $30 \%, 50 \%$ e $70 \%$. O sombreamento foi tipo simulado utilizando tela de coloração preta de nylon - Sombrite ${ }^{\circledR}$. 
Figura 1 - A: Acondicionamento das estacas em recipiente com água, B: preparo e enterrio das estacas no substrato, C: organização das unidades experimentais das mudas de hortelã.

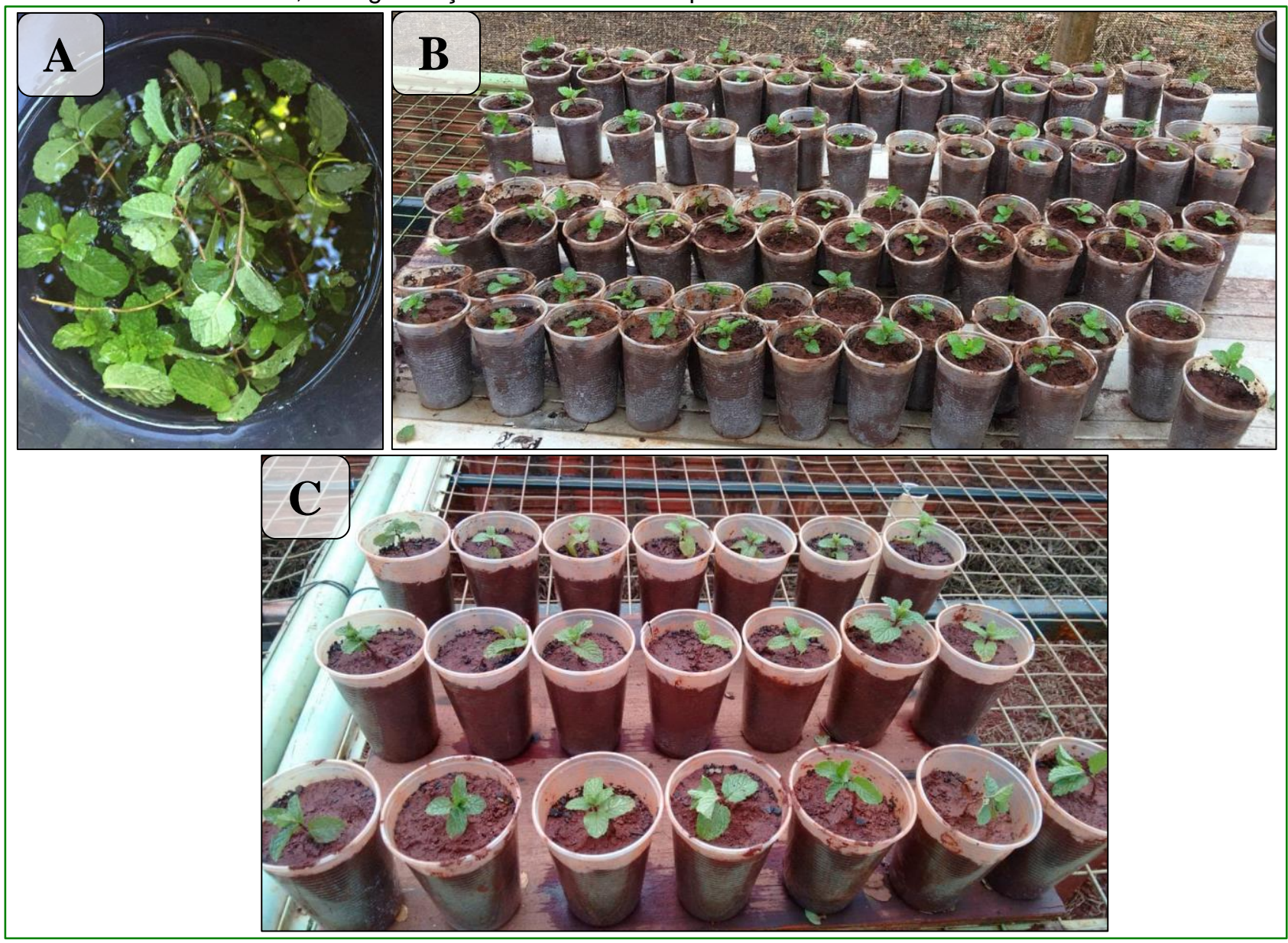

Fonte: Os autores.

O delineamento experimental adotado foi o inteiramente casualizado, com três repetições $(n=3)$, sendo que cada unidade experimental constituiu-se de sete recipientes com uma muda cada (Figura 1C). Durante a condução do experimento, o molhamento das mudas foi realizado manualmente com irrigador de bico fino, com dois turnos de rega diariamente.

Aos 75 dias após o enterrio das estacas foram avaliadas às seguintes características:

a) Sobrevivência: calculado a partir da equação: SOB (\%)= número de mudas vivas ao final do experimento, isto é, com brotações e folhas totalmente expandidas verdes/estacas na implantação x 100.

b) Crescimento: a altura das mudas foi medida com régua graduada $(\mathrm{cm})$, utilizando com padrão de avaliação a distância do coleto até a inflexão da folha mais alta; diâmetro do coleto $(\mathrm{mm})$ : com paquímetro digital inserido medido a $1,0 \mathrm{~cm}$ acima do nível do 
substrato. Foram contabilizadas o número de ramificações laterais e calculada a relação altura/diâmetro (RAD).

c) Índice de clorofila: utilizando clorofilômetro portátil CFL-1030 clorofiLOG (Falker Automação Agrícola, Porto Alegre, RS, Brasil), cuja determinação foi realizada entre as $8 \mathrm{e}$ $10 \mathrm{~h}$.

d) Área foliar, indicadores radiculares e massas frescas: as mudas foram colhidas, lavando as raízes para retirada do excesso de substrato. Então, determinaram-se a área foliar $\left(\mathrm{cm}^{2}\right)$ utilizando integrador de área (LI-COR, Modelo $3100 \mathrm{C}$ - Área Meter, Nebraska - USA), e o comprimento da maior raiz $(\mathrm{cm})$ com régua graduada. Contabilizou a percentagem de enraizamento, tendo como padrão de avaliação, a formação de raízes $\geq$ $5,0 \mathrm{~cm}$ (SANTOS et al., 2019). Considerando o fato de que geralmente a hortelã é comercializada fresca, realizou-se a pesagem da massa fresca de folhas, caules e raízes em balança de precisão $\left(0,0001 \mathrm{~g}\right.$ - Modelo Shimadzu $\left.{ }^{\circledR}\right)$.

Os dados foram submetidos à análise de variância (ANOVA), e quando significativos pelo teste $\mathrm{F}(p<0,05)$, as médias foram comparadas pelos testes de Tukey, para níveis de sombreamento $(p \leq 0,05)$, utilizando-se o software SISVAR (FERREIRA, 2019).

\section{RESULTADOS E DISCUSSÃO}

Em geral, as mudas de hortelã apresentaram respostas morfológicas variáveis de acordo com o nível de sombreamento, sendo que àquelas propagadas sob pleno sol $(0 \%$ de sombra) tiveram maior robustez considerando seu aspecto visual (Figura 2A). No entanto, as mudas propagadas sob $30 \%$ de sombra tiveram menor SOB $\%$ ( $81 \%)$, diferindo estatisticamente daquelas sob $50 \%$ e $70 \%$ de sombra, as quais apresentaram $100 \%$ de SOB (Figura 3A).

Constatamos que a maior altura das mudas $(27,37 \mathrm{~cm})$ ocorreu ao serem produzidas em ambiente com $70 \%$ de sombra em relação aos demais níveis de sombreamento testados (Figura 3B). A redução da intensidade luminosa incidente sobre as plantas induz maior investimento em parte aérea, ou seja, devido ao fato de haver maior quantidade de fotoassimilados disponíveis para o alongamento do caule, ocorre uma reação conhecida como "síndrome de evitar o sombreamento" ou "fuga ao sombreamento" (CHAGAS et al., 2010; FELSEMBURGH et al., 2016). Isso se deve ao fato de que nas condições de 
sombreamento podem ocorrer ajustes nas taxas metabólicas, alocando mais carbono para o caule, propiciando maior crescimento, esse comportamento pode também ser considerado uma estratégia de sobrevivência sob condições de baixa irradiância luminosa (SOUZA et al., 2018).

Figura 2 - Aspecto visual de mudas de hortelã propagadas por estaquia sob diferentes níveis de sombreamento: A: 0\% - pleno sol; B: 30\%; C: 50\% e D: 70\%.

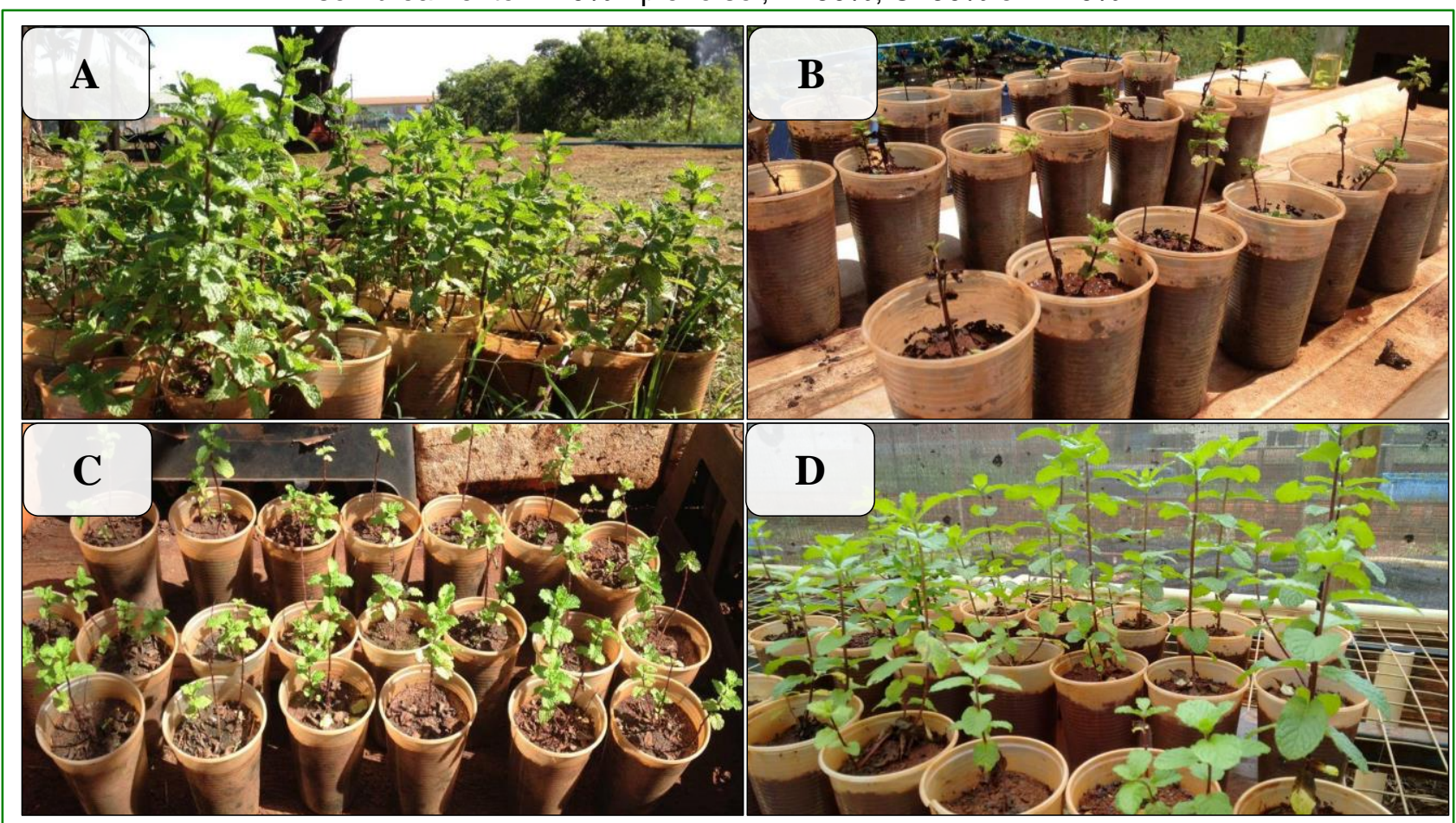

Fonte: Os autores.

Além disso, existe relação entre a disponibilidade luminosa e expressão de genes, induzida por fotorreceptores, que modificam as concentrações de fitohormônios endógenos, alterando o balanço de auxina, giberelina e citocinina, especialmente favorecendo a síntese de auxina e alongamento dos entrenós (COLON-CARMONA et al., 2000; MONTEIRO NETO et al., 2016).

Por outro lado, mudas à pleno sol tiveram maior $(2,42 \mathrm{~mm})$ diâmetro do coleto em comparação ao daquelas produzidas sob 30\% e 50\% de sombra (Figura 3C). O incremento em DC, especialmente em ambiente com alta irradiância, aqui representado por 0\% de sombra, demonstra que a espécie investe nessa característica, visando maior transporte de água e nutrientes nessa condição luminosa. De maneira semelhante, mudas de Lippia alba (Mill.) N.E. Brown também apresentaram maior DC sob pleno sol (SANTOS et al., 2019). 
Figura 3 - Sobrevivência - SOB (A), altura (B), diâmetro do coleto (C), relação altura/diâmetro - RAD (D), número de ramos $(E)$ e comprimento de raiz $(F)$ de mudas de hortelã propagadas por estaquia sob diferentes níveis de sombreamento. Letras iguais não diferem entre si (Tukey, $p<0,05)$. $(n=3)$.
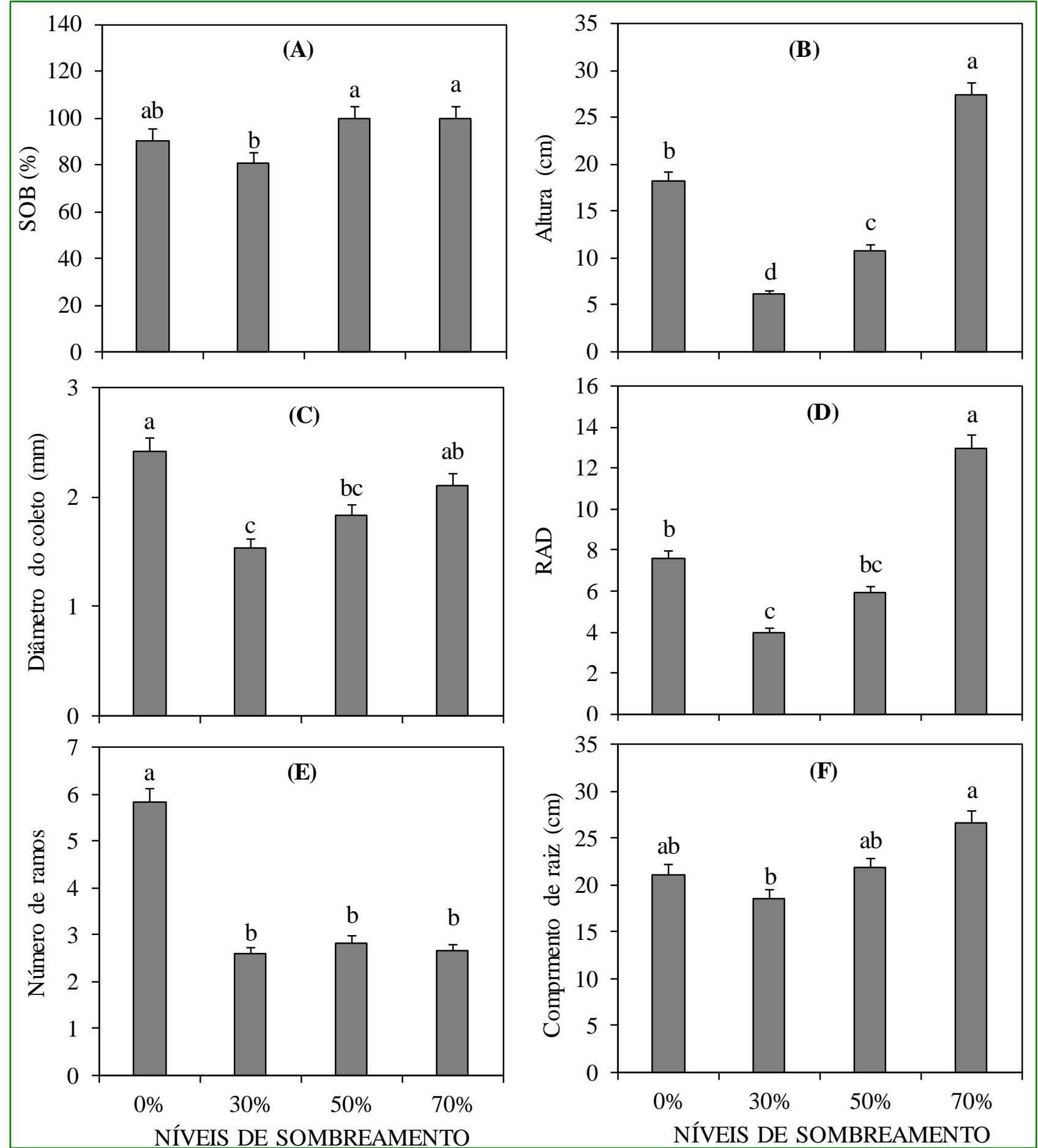

Quando as mudas apresentam aumento excessivo em altura, tal como observado em nosso estudo com a hortelã sob $70 \%$ de sombra, e essa característica não tem incremento proporcional em diâmetro, essas mudas são classificadas como estioladas, aqui representado pelo maior valor de $\operatorname{RAD}(12,96)$ (Figura 3D), especialmente considerando 
que a espécie é de baixo porte (herbácea). Nesse sentido, mudas com menores valores dessa característica indicam maior homeostase morfométrica, contribuindo em maior robustez da parte aérea, evitando possivelmente o tombamento das mudas. Resultados semelhantes foram observados por Gasparin et al. (2014), no qual mudas de Cabraelea canjerana (Vell.) Mart. apresentaram maior RAD em condição de 70\% de sombra. Todavia, os valores de RAD podem variar de acordo com a espécie, idade da muda, grau sucessional e hábito de crescimento.

Similar ao DC, o maior número de ramificações $(5,83)$ ocorreu nas mudas produzida à pleno sol (0\%), enquanto que nos demais níveis de sombreamento os valores foram menores e não diferiram estatisticamente entre si (Figura 3E). Considerando o fato de a espécie ser comercializada e/ou utilizada ainda fresca, quanto maior o número de ramificações, melhor será seu aproveitamento em função da maior quantidade de folhas em seus ramos, além de material disponível para posterior propagação.

No que se refere aos indicadores radiculares, a percentagem de enraizamento das mudas de hortelã não foi influenciada pelos níveis de sombreamento $(p>0,05)$, apresentando média de 100\%, demonstrando ser uma espécie de fácil rizogênese. Similarmente, Ferraz et al. (2018), avaliando o enraizamento de mudas do gênero Mentha sp. observaram que a espécie apresentou enraizamento > 85\%.

Por outro lado, o maior comprimento da raiz $(26,53 \mathrm{~cm})$ ocorreu nas mudas produzidas em 70\% de sombra (Figura 3F), apesar de não diferir estatisticamente daquelas à pleno sol e $50 \%$ de sombra, indicando plasticidade morfofisiológica aos diferentes gradientes luminosos para essa característica.

Ressaltamos que o fato de as mudas apresentarem melhor desenvolvimento radicular, não representa em sua totalidade que serão as mudas com maior vigor, uma vez que deve-se levar em consideração todos os aspectos das mudas, ou seja, as características devem apresentar particionamento de biomassa de maneira equilibrada entre a parte aérea e as raízes.

Em geral, as mudas produzidas em ambiente com sombreamentos intermediários, especialmente sob $30 \%$ de sombra apresentaram menores valores de todas as características avaliadas, não sendo indicada para a propagação dessa espécie nessas condições. De maneira semelhante ao nosso estudo com a hortelã ( $M$. x villosa Huds.), Costa et al. (2014), avaliando diferentes níveis de sombreamento em Mentha piperita L., 
espécie do mesmo gênero, observaram que suas mudas tiveram melhor desenvolvimento em cultivo à pleno sol.

Os maiores índices de clorofilas nas mudas à pleno sol e sob $70 \%$ de sombra $(28,07$ e 28,45 Falker, respectivamente) (Figura 4A), reforçam a ideia de que a hortelã apresenta plasticidade fisiológica aos ambientes contrastantes de luz. O aumento desses valores nessas condições luminosas deve-se a maior radiação fotossinteticamente ativa incidente em alta irradiância e maximização da capacidade fotossintética ( $\left.A_{\max }\right)$. Já em sombreamento intenso, essa resposta pode ser explicada como "estratégia de compensação", isto é, em virtude de haver menor disponibilidade luminosa ocorre incremento de pigmentos fotossintéticos (LIMA et al., 2011; SANTOS et al., 2019), visando manter os processos fisiológicos estáveis.

Figura 4 - Índice de clorofila (A) e área foliar (B) de mudas de hortelã propagadas por estaquia sob diferentes níveis de sombreamento. Letras iguais não diferem entre si (Tukey, $p<0,05)$. $(n=3)$

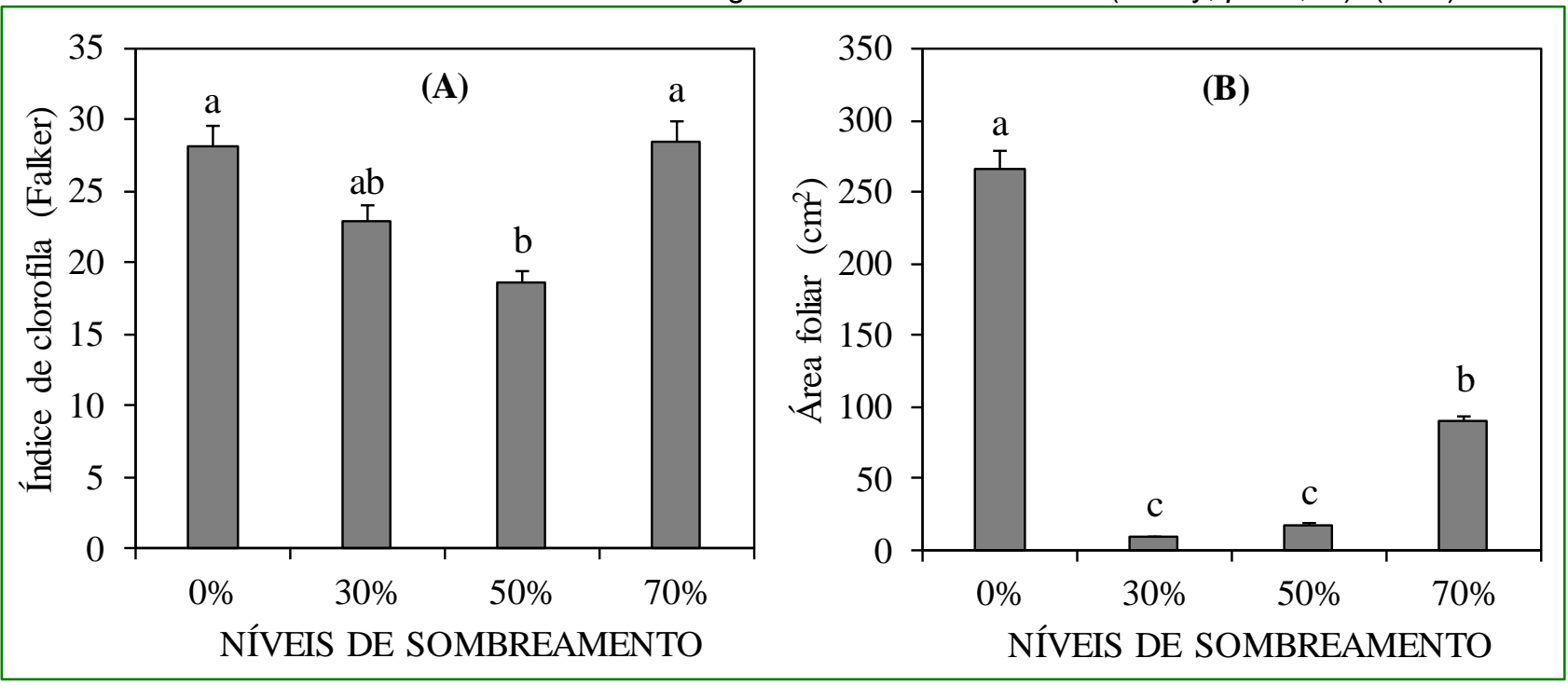

Fonte: Os autores.

A área foliar das mudas de hortelã apresentou resposta semelhante ao índice de clorofila, mas à pleno sol verificamos incremento pronunciado $\left(265,72 \mathrm{~cm}^{2}\right)$ dessa característica, diferindo-se estatisticamente dos valores nos demais níveis de sombreamento (Figura 4B). Esse maior valor está associado à quantidade de ramificações nessa mesma condição luminosa (Figura 3E), ou seja, maior número de folhas por ramos, promovendo maior área de intercepção luminosa.

Verificamos que em ambiente pleno sol (0\% de sombra) as mudas apresentaram maiores massas frescas de folhas, caules e raízes, com valores de 6,40; 6,27 e 6,00 
$\mathrm{g} /$ planta, respectivamente, diferindo-se estatisticamente das mudas nos demais níveis de sombreamento (Figura 5).

O aumento da disponibilidade luminosa promove incremento na espessura foliar (CASTRO et al., 1998; RIBEIRO et al., 2020). Consequentemente nessa condição também observamos maior quantidade de ramos (Figura 3E) e área foliar (Figura 4B), o que favoreceu maior produção de fotoassimilados e seu particionamento e acúmulo nos diferentes órgãos.

Figura 5 - Massas frescas de folhas (A), caule (B) e raízes (C) de mudas de hortelã propagadas por estaquia sob diferentes níveis de sombreamento. Letras iguais não diferem entre si (Tukey, $p<0,05)$. $(n=3)$

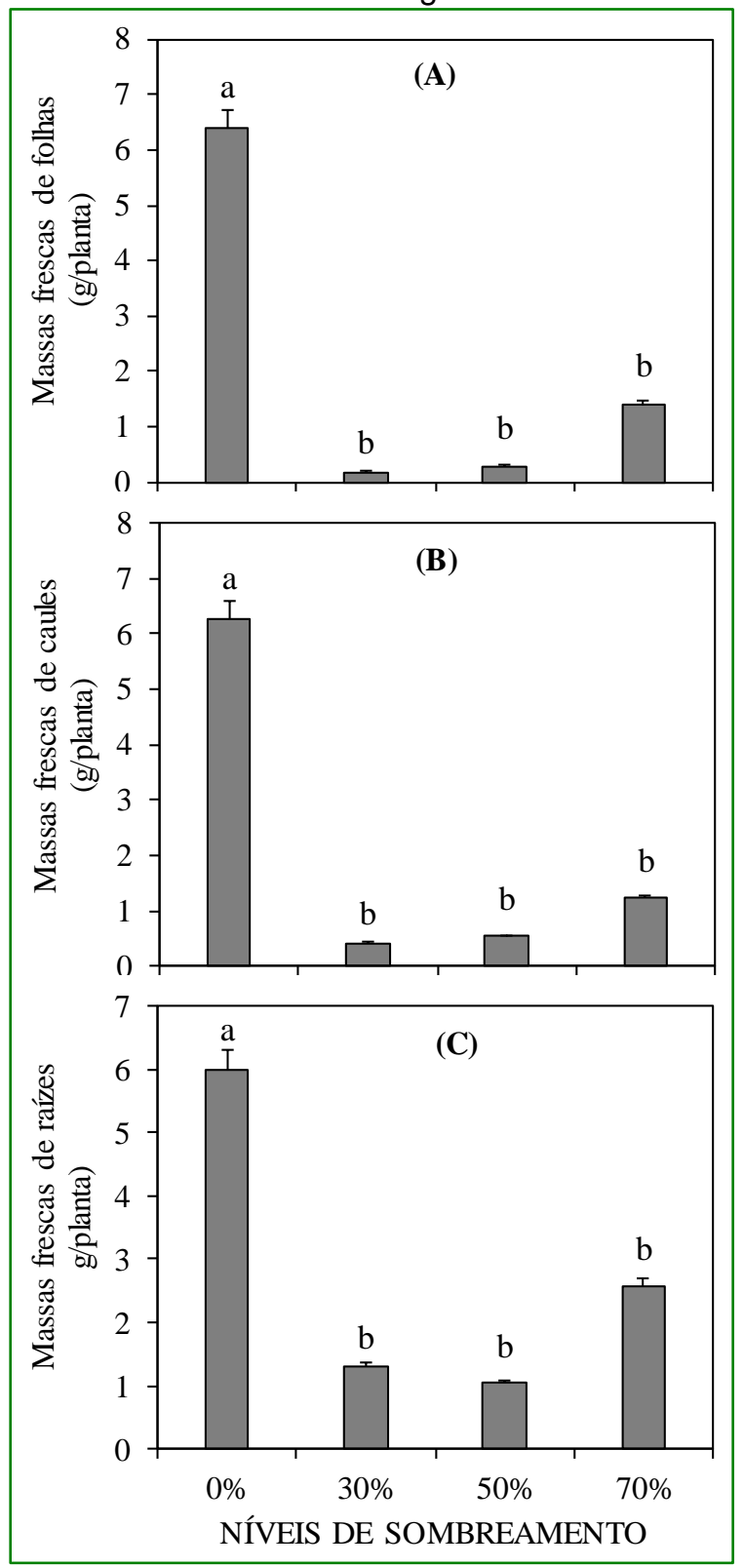

Fonte: Os autores. 
As informações obtidas nesse trabalho são subsídios para a propagação da $M . x$ villosa utilizando estacas. Em geral, observamos que mudas produzidas à pleno sol apresentam bons resultados, fato interessante uma vez que há redução de custos com tela de sombreamento, e ainda resultará em mudas mais tolerantes quando transplantadas às condições de campo, pois já estarão aclimatizadas à alta disponibilidade luminosa.

\section{CONCLUSÕES}

Com base em nossos resultados, confirmamos a hipótese de que o nível de sombreamento promove alteração na propagação vegetativa da hortelã por estaquia caulinar.

Mudas produzidas à pleno sol apresentam características mais viáveis para sua produção de biomassa.

\section{REFERÊNCIAS}

BRASIL. Ministério da Saúde. RENISUS - Relação Nacional de Plantas Medicinais de Interesse ao SUS. Espécies vegetais. DAF/SCTIE/MS - RENISUS - Fev/2009. Disponível em:

http://bvsms.saude.gov.br/bvs/sus/pdf/marco/ms_relacao_plantas_medicinais_sus_0603.p df. Acesso em 02/11/2020.

CASTRO, E. M.; GAVILANES, M. L.; ALVARENGA, A. A.; CASTRO, D. M. de; GAVILANES, T. O. T. Aspectos da anatomia foliar de mudas de Guarea guidonea (L.) Sleumer, sob diferentes níveis de sombreamento. Daphne, v. 8, n. 4, p. 31-35, 1998.

CHAGAS, J. H.; RIBEIRO, A. S.; PINTO, J. E. B. P.; BERTOLUCCI, S. K. V.; BOTREL, P. P.; COSTA, A, G. Análises foliares em plantas de Mentha arvensis L. cultivada sob diferentes malhas e níveis de sombreamento. Horticultura Brasileira, v. 28, n. 2, p. 3464$3471,2010$.

COLON-CARMONA, A.; CHEN, D. L.; YEH, K.; ABEL, S. Aux/IAA proteins are phosphorylated by phytochrome in vitro. Plant Physiology, v. 124, p. 1728-1738, 2000.

COSTA, A. G.; CHAGAS, J. H.; BERTOLUCCI, S. K. V.; PINTO, J. E. B. P. Níveis de sombreamento e tipos de malha no crescimento e produção de óleo essencial de hortelãpimenta. Horticultura Brasileira, v. 32, n. 2, p. 194-499, 2014.

COSTA, F. M.; ANJOS, G. L.; CAMILO, G. B. M.; OLIVEIRA, U. C.; SOUZA, G. S.; SANTOS, A. R. Produção de mudas de maracujazeiro amarelo em diferentes composições de substrato e ambiente. Revista de Ciências Agrárias, v. 41, n. 1, p. 138-146, 2018. 
COSTA, V. A.; JORGE, M. H. A.; COSTA, E.; CASTRO, A. R. R.; COSTA, M. L. N. Efeito de cortes de estacas e da presença de folhas na produção de mudas de Mentha sp. Revista Brasileira de Biociências, v. 14, n. 2, p. 55-59, 2016.

FELSEMBURGH, C. A.; SANTOS, K. J. S.; CAMARGO, P. B.; CARMO, J. B.; TRIBUZY, E. S. Respostas ecofisiológicas de Aniba parviflora ao sombreamento artificial. Pesquisa Florestal Brasileira, v. 36, n. 87, p. 201-210, 2016.

FERRAZ, Y. T.; MOTA, F. F. A.; ALVES, J. D. N.; MONFORT, L. E. F.; OKOMURA, R. S. Enraizamento de hortelã-verde (Mentha spicata) em diferentes tempos de exposição em ácido indolbutírico. Enciclopédia Biosfera, v. 15, n. 27, p. 198-208, 2018.

FERREIRA, D. F. Sisvar: a computer analysis system to fixed effects split plot type designs. Revista Brasileira de Biometria, v. 34, n. 4, p. 529-535, 2019.

FONSECA, M. C. M.; PINTO, C. L. O.; SEDYAMA, M. A. N.; SARTORATTO, A.; MACHADO, T. I.; DONZELES, S. M. L. Effect of drying temperature on the yield and phytochemical quality of the essential oil of mint (Menthax villosa Huds.). Brazilian Journal of Development, v. 6, n. 10, p. 81101-81112, 2020.

GASPARIN, E.; AVILA, A. L.; ARAUJO, M. M; FILHO, A. C.; DORNELES, D. U.; FOLTZ, D. R. B. Influência do substrato e do volume de recipiente na qualidade das mudas de Cabralea canjerana (Vell.) Mart. Em viveiro e no campo. Ciência Florestal, v. 24, n. 3, p. 553-563, 2014.

LIMA, M. C.; AMARANTE, L.; MARIOT, M. P.; SERPA, R. Crescimento e produção de pigmentos fotossintéticos em Achillea millefolium L. cultivada sob diferentes níveis de sombreamento e doses de nitrogênio. Ciência Rural, v. 41, n. 1, p. 45-50, 2011.

LIMA, M. G. A.; MAIA, I. C. C.; SOUSA, B. D.; MORAIS, S. M.; FREITAS, S. M. Effect of stalk and leaf extracts from Euphorbiaceae species on Aedes aegypti (Diptera, Culicidae) larvae. Revista do Instituto de Medicina Tropical de São Paulo, v. 48, n. 4, p. 211-214, 2006.

MARTINS, W. A.; MANTELLI, M.; SANTOS, S. C.; NETTO, A. P. C.; PINTO, F. Estaquia e concentração de reguladores vegetais no enraizamento de Campomanesia adamantium. Revista de Ciências Agrárias, v. 38, n. 1, p. 58-64, 2015.

MATOS-ROCHA, T. J.; CAVALCANTIA, M. G. S.; VERASA D. L.; SANTOS, E. A. F.; FREITAS, C. F.; SUASSUNAC, A. S. C. L.; MELO, S.; BARBOSA-FILHO, J. M.; ALVESA, L. C.; SANTOS, F. A, B. In vivo effect of essential oil of Mentha x villosa and its active compound against Schistosoma mansoni (Sambon, 1907). Brazilian Journal of Biology, v. 80 , n. 3, p. 582-588, 2020.

MESSIAS, M. C. T. B.; MENEGATTO, M. F.; PRADO, A. C. C.; SANTOS B. R.; GUIMARÃES, M. F. M. Uso popular de plantas medicinais e perfil socioeconômico dos usuários: um estudo em área urbana em Ouro Preto, MG, Brasil. Revista Brasileira de Plantas Medicinais, v. 17, n. 1, p. 76-104, 2015. 
MONTEIRO NETO, J. L. M.; ARAÚJO, W. F.; VILARINHO, L. B. O.; SILVA, E. S.; ARAÚJO, W. B. L.; SAKAZAKI, R. T. Produção de mudas de pimentão (Capsicum annum L.) em diferentes ambientes e substratos. Revista Brasileira de Ciências Agrárias, v. 11, n. 4, p. 289-297, 2016.

NASCIMENTO, E. M.; FURLONG, J.; PIMENTA, D. S.; PRATA, M. C. A. Efeito antihelmíntico do hidrolato de Mentha x villosa Huds. (Lamiaceae) em nematoides gastrintestinais de bovinos. Ciência Rural, v. 39, n. 3, p. 817-824, 2009.

PAULUS, D.; PAULUS, E. Efeito de substratos agrícolas na produção de mudas de hortelã propagadas por estaquia. Horticultura Brasileira, v. 25, n. 4, p. 594-7, 2007.

REIS, S. M.; MARIMON'JÚNIOR, B. H.; MORANDI, P. S.; OLIVEIRA-SANTOS, C.; OLIVEIRA, B.; MARIMON. B. S. Desenvolvimento inicial e qualidade de mudas de Copaifera langsdorffii Desf. Sob diferentes níveis de sombreamento. Ciência Florestal, v. 26, n. 1, p. 11-20, 2016.

RIBEIRO, L.; CATEN, A. T.; JUNIOR, P. C. P. Plasticidade fenotípica de caracteres morfofisiológicos e reflexão espectral de folhas de llex paraguariensis A. St.-Hil. Enciclopédia Biosfera, v. 17, n. 31, p. 170-185, 2020.

SANTOS, C. C.; FRANCO-RODRIGUEZ, A.; ARAUJO, G. M.; SCALON, S. P.; VIEIRA, M. C. Impact $f$ phosphorus and luminosity on the propagation, photochemical reactions and quality of Lippia alba (Mill.) N.E.Br. seedlings. Revista Colombiana de Ciências Hortícolas, v. 13, n. 2, p. 291-302, 2019.

SANTOS, C. C.; LIMA, N. M.; VIEIRA, M. C.; ZÁRATE, N. A. H.; SCALON, S. P. Q. Metabolismo fotossintético em mudas de Pereskia aculeata Plum. propagadas por estaquia sob diferentes disponibilidades luminosas. Revista de Ciências Agrárias, v. 42, n. 3, p. 712-719, 2019.

SILVA, F. C. Manual de análises químicas do solo, plantas e fertilizantes. 2. ed. rev. ampliada-Brasília, DF: Embrapa Informação Tecnológica, 2009. 627 p.

SOUZA, R. R.; FREIRE, A. L. O. Relação entre o sombreamento, o crescimento, e a qualidade de mudas de craibeira. Scientia Agraria Paranaensis, v. 17, n. 2, p. 220-225, 2018. 


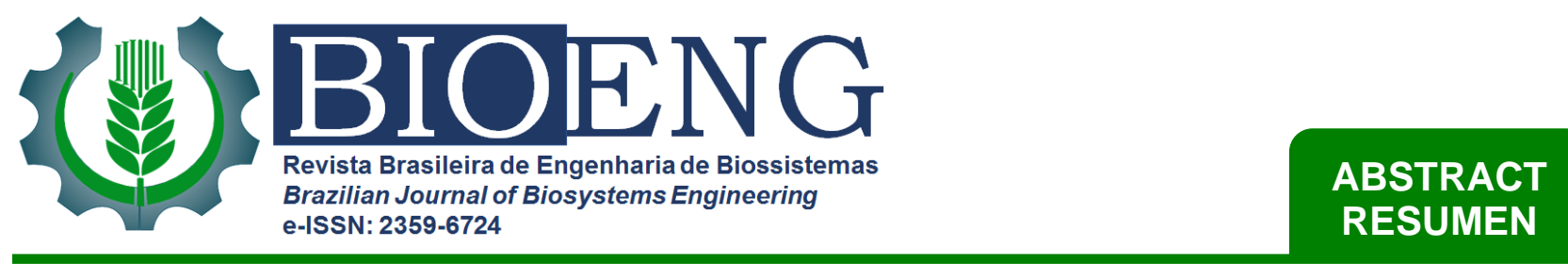

\section{ABSTRACT}

The mint (Mentha $\mathrm{x}$ villosa Huds., Lamiaceae) is a medicinal and aromatic plant, generally used on the preparation of teas and juices. Through this study it was assumed that levels of light interception of the seedlings production environment can influence vegetative propagation of mint. The experiment was carried out, evaluating four luminous availability based on the shading levels of $0 \%$ (full sun), $30 \%, 50 \%$ and $70 \%$. The cuttings were collected in the morning, packed in a container with water, and standardized with $7.0 \mathrm{~cm}$ long and four leaves. Subsequently, $1 / 3$ cutting was buried in substrate consisting of Dystrophic Red Latosol + Tropstrato $^{\circledR}(3: 1, \mathrm{v} / \mathrm{v})$. The evaluations of non-destructive and destructive characteristics were performed at 75 days after the burial of the cuttings. In general, the mint seedlings showed values of survival $>80 \%$. The highest height, root length and height/diameter ratio occurred in seedlings produced under $70 \%$ shade. On the other hand, seedlings produced in full sun (0\%) have higher number of branches, leaf area, and fresh mass production of leaves, stem and roots. It is recommended for production of mint seedlings that their vegetative propagation by cuttings be made in environment under full sun.

Keywords: Cuttings. Etiolation. Light. Medicinal plant. Vegetative propagation.

\section{RESUMEN}

La menta (Mentha x villosa Huds., Lamiaceae) es una planta medicinal y aromática, generalmente utilizada en el preparo de infusiones y jugos. En este estudio se supuso que el nivel de intercepción luminosa del ambiente de producción de plántulas puede influenciar en la propagación vegetativa de la menta. La investigación se realizó, evaluando cuatro disponibilidades luminosas basándose en los niveles de sombra de $\%$ (pleno sol), $30 \%$, $50 \%$ y $70 \%$. Las estacas fueron cogidas en el periodo matutino, acondicionadas en recipiente con agua, y estandarizadas con $7,0 \mathrm{~cm}$ de largura y cuatro hojas. Después, se realizó el entierro de $1 / 3$ de la estaca en sustrato constituido de Farralsol Rojo Distroférrico + Tropstrato ${ }^{\circledR}(3: 1, \mathrm{v} / \mathrm{v})$. Las evaluaciones de las características no destructiva y destructivas fueron realizadas a los 75 días después del entierro de las estacas. En general, las plántulas de menta presentaron valores de sobrevivencia $>80 \%$. El valor de altura más grande, largura de la raíz y relación altura/diámetro ocurrió en las plántulas producidas con $70 \%$ de sombra. Por otro lado, plántulas producidas à pleno sol $(0 \%)$ presentan numero de brotes, área foliar y producción de masa fresca de hojas, tallos y raíces más grande. Se recomienda, para la producción de plántulas de menta, que su propagación vegetativa por estacas se haga en ambiente a pleno sol.

Palabras clave: Estaquia. Desglose. Luminosidad. Planta medicinal. Propagación vegetativa. 


\section{LICENÇA DE USO}

Este é um artigo publicado em acesso aberto (Open Access) sob a licença Creative Commons Atribuição 4.0 Internacional (CC BY 4.0), que permite uso, distribuição e reprodução em qualquer meio, desde que o trabalho original seja corretamente citado. Mais informações em: http://creativecommons.org/licenses/by/4.0

\section{CONFLITO DE INTERESSES}

Os autores declaram que não há conflito de interesses neste trabalho.

\section{CONTRIBUIÇÕES AUTORAIS}

Elias Vinícius Wanderline Quaresma: responsável pela condução experimental, coleta de dados, interpretação estatística e redação científica.

Rodrigo Pereira de Assis Otto: responsável pela condução experimental, coleta de dados, interpretação e redação científica.

Cleberton Correia Santos: responsável pelo planejamento, análises estatísticas, redação e revisão do manuscrito.

Juliana Milene Silverio: responsável pela interpretação estatística e redação científica. Guilherme Henrique de Souza Loli: responsável pela condução experimental, coleta de dados e redação científica.

Maria do Carmo Vieira: responsável pela revisão do manuscrito.

\section{FINANCIAMENTO}

Os autores agradecem ao Conselho Nacional de Desenvolvimento Científico e Tecnológico (CNPq) e Coordenação de Aperfeiçoamento de Pessoa de Nível Superior (CAPES), pela concessão de bolsas, e à Fundação de Apoio ao Desenvolvimento de Ensino, Ciência e Tecnologia do Mato Grosso do Sul (FUNDECT), pelo apoio financeiro.

\section{COMO REFERENCIAR}

QUARESMA, Elias Vinícius Wanderline; OTTO, Rodrigo Pereira de Assis; SANTOS, Cleberton Correia; SILVERIO, Juliana Milene; LOLI, Guilherme Henrique de Souza; VIEIRA, Maria do Carmo. Níveis de sombreamento influenciam a produção de mudas de Mentha x villosa Huds. (hortelã). Revista Brasileira de Engenharia de Biossistemas (Tupã), v. 15, n. 1, p. 127-141, 2021. DOl:

http://dx.doi.org/10.18011/bioeng2021v15n1p127-141.

\section{RESPONSABILIBADE EDITORIAL}

Prof. Dr. Fernando Ferrari Putti ${ }^{1}$, Prof. Dr. Paulo Sérgio Barbosa dos Santos ${ }^{1}$, Prof. Dr. Eduardo Festozo Vicente ${ }^{1}$ e Prof. Dr. Diogo de Lucca Sartori ${ }^{1}$

1 Universidade Estadual Paulista "Júlio de Mesquita Filho", FCE - Faculdade de Ciências e Engenharia, Tupã, SP, Brasil. 